\title{
Photosynthesis-nitrogen relationship in a Hinoki cypress (Chamaecyparis obtusa) canopy: a comparison with Japanese cedar (Cryptomeria japonica)
}

\author{
H. KOBAYASHI ${ }^{*, * * *,}$, S. INOUE ${ }^{* *, \#}$, and K. GYOKUSEN ${ }^{* *}$ \\ Research Institute of Kyushu University Forests, Fukuoka 811-2415, Japan ${ }^{*}$ \\ Graduate School of Bioresource and Bioenvironmental Sciences, Kyushu University, Fukuoka 812-8581, Japan ${ }^{* *}$
}

\begin{abstract}
The relationship between light-saturated photosynthetic capacity $\left(P_{\max }\right)$ and leaf nitrogen $(\mathrm{N})$ content was investigated for one year in a 15-year-old Chamaecyparis obtusa canopy and was compared with a Cryptomeria japonica canopy previously described. The linear regression between $P_{\max }$ and leaf $\mathrm{N}$ content tended to converge toward a single line segment from July to January and in May for C. obtusa. The slope of the linear regression between $P_{\max }$ and leaf $\mathrm{N}$ content of $C$. obtusa was gentler than that of $C$. japonica. The smaller regression coefficient of $C$. obtusa may reflect species differences in nitrogen nutrition requirements between C. obtusa and C. japonica. A pronounced decrease in the slope of the linear regression lines due to low temperature was observed in February and March. During this period, $P_{\max }$ of $C$. obtusa declined more than that of $C$. japonica suggesting that $C$. obtusa is less tolerant to low temperatures than C. japonica.
\end{abstract}

Additional key words: leaf nitrogen content; photosynthetic capacity; species difference; winter depression.

The Hinoki cypress [Chamaecyparis obtusa (Sieb. et Zucc.) Endl.] is a common plantation species that has become a symbol of Japanese traditional culture, together with the Japanese cedar (Cryptomeria japonica D. Don). C. obtusa and $C$. japonica have geographically similar natural distributions, and the planting area of the two species accounts for $65 \%$ of the total plantation area in Japan (C. obtusa 25\%, C. japonica 40\%). Recently, carbon dioxide $\left(\mathrm{CO}_{2}\right)$ absorption by these plantations has received attention from the standpoint of carbon sequestration and climate-change mitigation (e.g., Cannell 1999, Jandl et al. 2007).

The light-saturated photosynthetic capacity $\left(P_{\max }\right)$ is positively correlated with leaf nitrogen $(\mathrm{N})$ content in many plant species (Field and Mooney 1986). Using the $P_{\max }-\mathrm{N}$ relationship, the amount of $\mathrm{CO}_{2}$ absorption has been calculated based on the leaf $\mathrm{N}$ content in many plant canopies (e.g., Hirose and Werger 1987, Hollinger 1996) including C. japonica (Kobayashi 2010). However, less information is available on photosynthetic traits for C. obtusa than for $C$. japonica, including the $P_{\max }-\mathrm{N}$ relationship and temperature dependency. In this study, we measured the $P_{\max } \mathrm{N}$ relationship in a $C$. obtusa canopy over the course of a year and compared the results with the data for $C$. japonica, which we had described previously (Kobayashi et al. 2010).

Measurements were made in the Fukuoka Research Forest, a Kyushu University Forest located in Fukuoka, southwest Japan $\left(33^{\circ} 38^{\prime} \mathrm{N}, 130^{\circ} 31^{\prime} \mathrm{E}, 79 \mathrm{~m}\right.$ a.s.1.). The climatic zone of this area is warm-temperate. According to the annual report of the Kyushu University Forests for the study period from 2000 to 2001 , the mean annual air temperature and annual precipitation were $15.8^{\circ} \mathrm{C}$ and $1,250 \mathrm{~mm}$ in 2000 , and $15.7^{\circ} \mathrm{C}$ and $1,730 \mathrm{~mm}$ in 2001 (Fig. 1A).

A 15-year-old stand of C. obtusa, planted at a density of 3,000 trees per hectare, was used in this study. Three neighboring trees of typical height and diameter

Received 21 July 2010, accepted 6 March 2012.

${ }^{+}$Corresponding author; fax: $+81-265-77-1533$, e-mail: kobaafc@shinshu-u.ac.jp; ${ }^{* * *}$ present address: Education and Research Center of Alpine Field Science, Shinshu University, 8304 Minamiminowa, Nagano 399-4598, Japan; ${ }^{\#}$ present address: Tsukuba Research Institute, Sumitomo Forestry CO., LTD., Ibaragi 300-2646, Japan

Abbreviations: $\mathrm{N}$ - nitrogen; $P_{\max }$ - light-saturated photosynthetic capacity; PPFD - photosynthetic photon flux density; R-PPFD relative photosynthetic photon flux density.

Acknowledgements: We thank the staff and students of the Research Institute of Kyushu University Forests for kindly supporting our work. We also thank our anonymous reviewers for helpful comments leading to an improved manuscript. 
were used for the measurements $(n=3)$. The canopy was closed, and the mean tree height was $9.6 \mathrm{~m}$ and the height of the lowest live branch was $3.3 \mathrm{~m}$. The mean diameter at breast height was $14 \mathrm{~cm}$. Scaffolding was erected to provide access to the canopy. The tree canopies were divided into six layers at equal intervals from the top to the bottom. Three primary branches diverging from the trunk were selected from the three trees (one branch per tree) in each canopy layer. All primary branches were selected from the southern side of the canopy.

The light-saturated rate of photosynthesis of thirdorder leaves (i.e., 0- to 1-year-old leaves) was measured intact at the tip of each primary branch using a portable open gas exchange system ( $L C A-4, A D C$ BioScientific, Hoddesdon, UK). Leaves in each canopy layer were measured monthly from June 2000 to May 2001. Measurements were performed between 08:00 $\mathrm{h}$ and 11:00 $\mathrm{h}$ with a photosynthetic photon flux density (PPFD) (400 to $700 \mathrm{~nm}$ ) over $1,400 \mu \mathrm{mol} \mathrm{m} \mathrm{s}^{-2}$ and at ambient $\mathrm{CO}_{2}$ concentration (334 to $382 \mathrm{ppm}$ ), air temperature (15 to $38^{\circ} \mathrm{C}$ ), and relative humidity $(21$ to $64 \%$ ) on clear days. Stems and branches in the upper portion of the canopy were moved aside to provide sufficient light in the lower portion of the canopy. After the gas-exchange measurements, each leaf was excised from its branch, and the projected area, dry mass, and $\mathrm{N}$ concentration were determined. Leaves were placed horizontally on a flatbed image scanner (GT-5500, Epson, Suwa, Japan), and their projected area was measured. The dry mass of each leaf was measured after drying at $65^{\circ} \mathrm{C}$ for $48 \mathrm{~h}$. The leaf dry mass was divided by the leaf-projected area to obtain the leaf mass per area $\left(\mathrm{g} \mathrm{m}^{-2}\right)$. The $\mathrm{N}$ concentration $[\mathrm{mg}(\mathrm{N})$ $\mathrm{g}^{-1}$ ] was determined with a $\mathrm{CN}$ analyzer (MT-700, Yanaco, Kyoto, Japan). The $\mathrm{N}$ concentration and leaf mass per area were multiplied to express the leaf $\mathrm{N}$ content on an area basis $\left[\mathrm{g}(\mathrm{N}) \mathrm{m}^{-2}\right]$.

The PPFD was measured within a week after the gasexchange measurement with a level quantum sensor ( $L I$ 190SA, Li-Cor, Lincoln, USA) and recorded with a $\mathrm{Li}$-Cor data logger (LI-1400). The relative PPFD was calculated against a reference PPFD measured simultaneously above the canopy. Measurements were taken between 10:00 $\mathrm{h}$ and 14:00 $\mathrm{h}$ under an overcast sky.

A two-way analysis of variance $(A N O V A)$ was used to test the effects of spatial (canopy layer) and temporal (sampling date) variations on $P_{\max }$ and the leaf $\mathrm{N}$ content. Linear regression was performed with $P_{\max }$ as a dependent variable against the leaf $\mathrm{N}$ content. Differences in the slope and $y$-intercept of the linear regression between sampling dates and between species were tested by an analysis of covariance $(A N C O V A)$. All tests of significance were set at $P<0.05$. Statistical analyses were carried out using the STATISTICA 5.OJ computer software package (StatSoft, Tulsa, USA).

The relative PPFD (R-PPFD) in a C. obtusa canopy decreased from June to October, then remained steady thereafter in each canopy layer (Fig. 1B). This seasonal

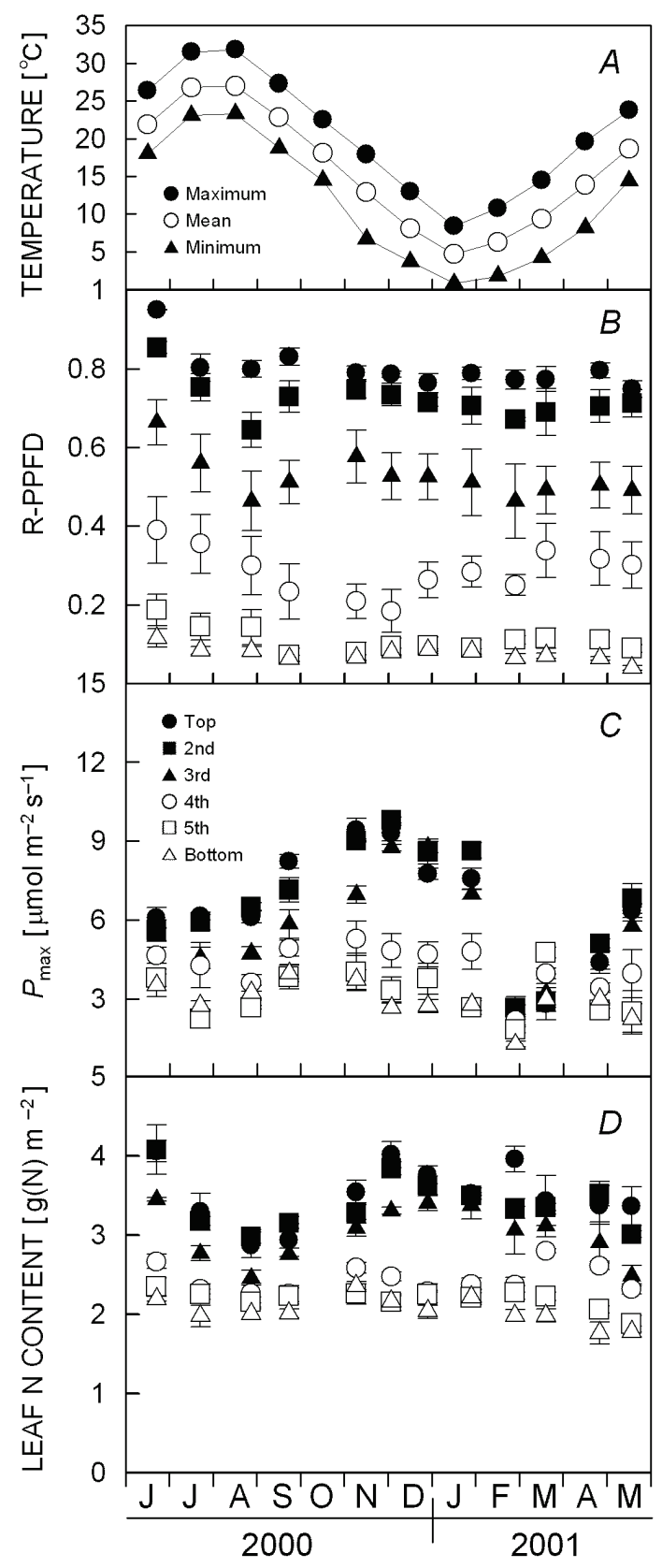

Fig. 1. Temporal variations in $(A)$ maximum, minimum, and mean air temperature, $(B)$ relative photosynthetic photon flux density (R-PPFD), (C) light-saturated photosynthetic capacity $\left(P_{\max }\right)$, and $(D)$ leaf nitrogen content from June 2000 to May 2001. Meteorological data were collected at the arboretum in the Fukuoka Research Forest of the Kyushu University Forests. Panel $A$ was redrawn after Kobayashi et al. (2010). $A$ : $\bullet$ - the maximum air temperature, $\boldsymbol{\Delta}$ - the minimum air temperature, and $\circ$ - the mean air temperature. Canopy data were collected in a 15-year-old Chamaecyparis obtusa canopy. Means and standard errors of means $(n=3)$ are indicated in Figs. $(B),(C)$, and $(D) . B, C, D: \bullet-$ the top layer, - the $2^{\text {nd }}$ layer, $\boldsymbol{\Delta}-$ the $3^{\text {rd }}$ layer, $\circ-$ the $4^{\text {th }}$ layer, $\square-$ the $5^{\text {th }}$ layer, and $\Delta-$ the bottom layer of the canopies. 


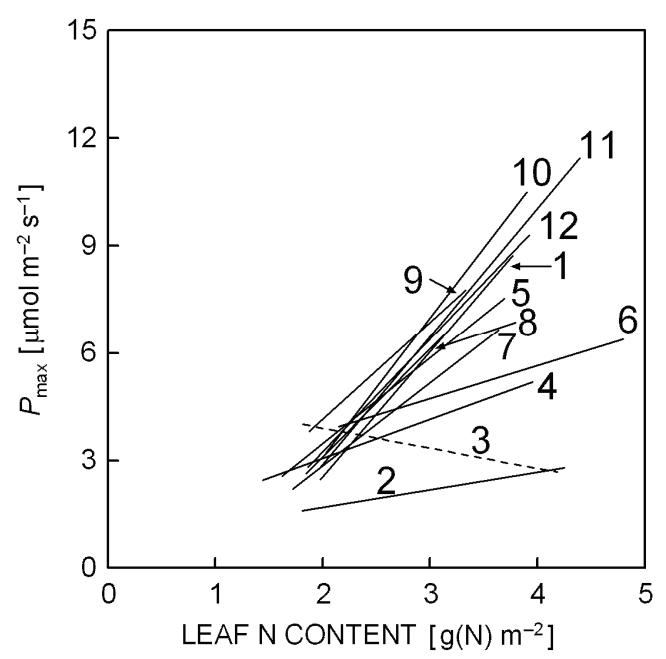

Fig. 2. Linear regression equations between leaf nitrogen content and light-saturated photosynthetic capacity $\left(P_{\max }\right)$ for the given sampling dates in a 15-year-old Chamaecyparis obtusa canopy. The numbers beside the regressions refer to the months. The linear regression for March (dashed line) was not significant $(P=0.219)$. Linear regressions are June: $\mathrm{y}=1.98+$ $0.92 \mathrm{x}, r=0.660, P<0.01$; July: $\mathrm{y}=-1.78+2.32 \mathrm{x}, r=0.749$, $P<0.001$; August: $\mathrm{y}=-2.96+3.03 \mathrm{x}, r=0.820, P<0.001$; September: $\mathrm{y}=-1.31+2.72 \mathrm{x}, r=0.715, P<0.001$; October: $\mathrm{y}=-4.67+3.89 \mathrm{x}, r=0.837, P<0.001 ;$ November: $\mathrm{y}=-4.27+$ $3.58 \mathrm{x}, r=0.938, P<0.001$; December: $\mathrm{y}=-3.10+3.16 \mathrm{x}$, $r=0.926, P<0.001$; January: $\mathrm{y}=-4.45+3.50 \mathrm{x}, r=0.905$, $P<0.001$; February: y $=0.70+0.49 \mathrm{x}, r=0.586, P<0.05$; March: $\mathrm{y}=5.02-0.56 \mathrm{x}, r=0.305, P>0.05$; April: $\mathrm{y}=0.87+$ $1.09 \mathrm{x}, r=0.742, P<0.001$; May: $\mathrm{y}=-1.34+2.41 \mathrm{x}, r=0.701$, $P<0.01$.

trajectory of temporal variation in R-PPFD represents shoot elongation in the $C$. obtusa canopy. R-PPFD decreased with increasing depth from the top of the canopy, ranging from maximum values of 0.95 to 0.71 in the uppermost layer of the canopy to minimum values of 0.17 to 0.03 in the bottom layer.

The $P_{\max }$ and leaf $\mathrm{N}$ content differed significantly between canopy layers $\left(P_{\max }: F=41.3, P<0.001\right.$; leaf N: $F=10.6, P<0.001)$. Both $P_{\max }$ and leaf $\mathrm{N}$ content decreased with increasing depth from the top of the canopy (Figs. $1 C, D$ ) and were significantly correlated with R-PPFD on each sampling date $\left(P_{\max }: r=0.519\right.$ to 0.949 ; leaf $\mathrm{N}$ content: $r=0.777$ to 0.961$)$. As a consequence, a significant correlation was observed between $P_{\max }$ and leaf $\mathrm{N}$ content on each sampling date except in March (Fig. 2). The $P_{\max }$ and leaf $\mathrm{N}$ content also differed significantly between sampling dates $\left(P_{\max }: F=126\right.$, $P<0.001$; leaf $\mathrm{N}: F=195, P<0.001)$. However, the seasonal trajectory of the temporal variation in $P_{\max }$ differed from that of the leaf $\mathrm{N}$ content. $P_{\max }$ increased from June to November, then decreased until February, and increased thereafter (Fig. 1C). The leaf $\mathrm{N}$ content decreased from June to August, then increased until
November, and decreased gradually thereafter (Fig. 1D). As a consequence, the slope of the linear regression between $P_{\max }$ and leaf $\mathrm{N}$ content differed significantly between sampling dates $(F=12.50, P<0.001)$. The linear regression between $P_{\max }$ and leaf $\mathrm{N}$ content tended to converge toward a single line segment from July to January and in May (Fig. 2). Pooled data for these eight sampling dates yield a linear equation of $\mathrm{y}=-3.16+$ $3.17 \mathrm{x}, r=0.843, P<0.001$, representing a more gentle slope than that of $C$. japonica $(\mathrm{y}=-5.81+4.50 \mathrm{x}$, Kobayashi et al. 2010), obtained from similar sampling period (August, October, November, December and April). The slope of linear regression between $P_{\max }$ and leaf $\mathrm{N}$ content of $C$. obtusa was significantly lower than $C$. japonica for data pooled for August and October $(F=4.66, P<0.05)$. The slope of the $P_{\max }-\mathrm{N}$ relationship reflects the sensitivity of tree growth to nitrogen nutrition. Photosynthesis (Nagasaki and Gyokusen 2006) and whole plant biomass (Nagakura et al. 2005) of C. obtusa are less sensitive to nitrogen nutrition than those for $C$. japonica. Thus, the gentler slope of C. obtusa may reflect species differences in nitrogen nutrition requirements between $C$. obtusa and $C$. japonica. A pronounced decrease in the slope of the linear regression lines was observed below the converged line segment in June, February, March, and April. These reductions in $P_{\max }$ did not accompany a reduction in leaf $\mathrm{N}$ content. An obvious shoot elongation was observed in C. obtusa in June (Fig. 1B). Therefore, we conclude that the leaves of $C$. obtusa were not yet functionally developed, and that high photosynthesis could not be attained in June. $P_{\max }$ in $C$. obtusa might be reduced due to low temperatures in February and March (Fig. 1A), the same as in C. japonica (Kobayashi et al. 2010). During this period, $P_{\max }$ declined to nearly a quarter of its maximum potential, as estimated from the equation for the converged line segment, and recovered to just half of its maximum in April. In contrast, $P_{\max }$ of $C$. japonica fell to only half of its maximum in winter (Kobayashi et al. 2010). Furthermore, $P_{\max }$ of $C$. japonica recovered to its maximum in early April. Takase et al. (2010) measured $P_{\max }$ in $C$. obtusa and $C$. japonica during winter. They demonstrated that winter depression in $P_{\max }$ was greater in C. obtusa than in C. japonica. Furthermore, they reported that $P_{\max }$ of $C$. obtusa required a longer recovery period than $C$. japonica from winter depression in spring. Our study is consistent with their results. These facts suggest that C. obtusa is less tolerant to low temperatures than $C$. japonica. We have no definite information as to why $P_{\max }$ was lowest in February rather than January, when the mean monthly air temperature was lowest (Fig. 1A,C). The precise process of cold acclimation in C. obtusa is less known than for $C$. japonica (Hashimoto and Suzaki 1978, Tange 1996, Han et al. 2003, 2004), and further study is necessary. 


\section{References}

Cannell, M.G.R.: Growing trees to sequester carbon in the UK: answers to some common questions. - Forestry 72: 237-247, 1999.

Field, C., Mooney, H.A.: The photosynthesis-nitrogen relationship in wild plants. - In: Givnish, T.J. (ed.): On the Economy of Plant Form and Function. Pp. 25-55. Cambridge Univ. Press, Cambridge 1986.

Han, Q., Katahata, S., Kakubari, Y., Mukai, Y.: Seasonal changes in the xanthophyll cycle and antioxidants in sunexposed and shaded parts of the crown of Cryptomeria japonica in relation to rhodoxanthin accumulation during cold acclimation. - Tree Physiol. 24: 609-616, 2004.

Han, Q., Shinohara, K., Kakubari, Y., Mukai, Y.: Photoprotective role of rhodoxanthin during cold acclimation in Cryptomeria japonica. - Plant Cell Environ. 26: 715-723, 2003.

Hashimoto, R., Suzaki, T.: Resistances to carbon dioxide transfer in leaves of Cryptomeria joponica in winter, and influences of soil temperature on them. - J. Japan Forest Soc. 60: $24-30,1978$.

Hirose, T., Werger, M.J.A.: Maximizing daily canopy photosynthesis with respect to the leaf nitrogen allocation pattern in the canopy. - Oecologia 72: 520-526, 1987.

Hollinger, D.Y.: Optimality and nitrogen allocation in a tree canopy. - Tree Physiol. 16: 627-634, 1996.

Jandl, R., Vesterdal, L., Olsson, M., Bens, O., Badeck, F., Roc, J.: Carbon sequestration and forest management. - $\mathrm{CAB}$
Reviews 2: $\vee$ No. 017, 16 pp??? Is it correct? Pages from - to $\vee ?, 2007$.

Kobayashi, H.: [Effect of thinning on carbon dioxide absorption in a Cryptomeria japonica canopy. Valuation using canopy photosynthesis model.] - Bull. Shinshu Univ. AFC 8: 77-80, 2010. [In Japan.]

Kobayashi, H., Inoue, S., Gyokusen, K.: Spatial and temporal variations in the photosynthesis-nitrogen relationship in a Japanese cedar (Cryptomeria japonica D. Don) canopy. Photosynthetica 48: 249-256, 2010

Nagakura, J., Shigenaga, H., Akama, A., Takahashi, M.: Effects of soil moisture and nitrogen on growth responses of Cryptomeria japonica and Chamaecyparis obtusa seedlings. Phyton 45: 423-428, 2005.

Nagasaki, M., Gyokusen, K.: [Photosynthesis and stomatal conductance of Japanese cedar and Hinoki cypress in response to fertilization and soil drying.] - Kyushu J. Forest Res. 59: 180-182, 2006. [In Japan.]

Takase, M., Sakuta, K., Gyokusen, K.: [Comparison of photosynthesis between Cryptomeria japonica and Chamaecyparis obtusa during winter.] $-121^{\text {th }}$ Annual Meeting of the Jap. Forest Soc. Tsukuba, Japan, Pc2-12, 2010. [In Japan.]

Tange, T.: Seasonal changes in photosynthesis of young Cryptomeria japonica growing on ridges and foot-slopes. Forest Ecol. Manage. 89: 93-99, 1996. 